\title{
Keratometric changes after cataract extraction
}

\author{
DHANWANT SINGH* AND KIRANJIT KUMAR† \\ From the Rajindra Hospital, Patiala, India,* and the Civil Hospital, Faridkot, India $\dagger$
}

Since Donders (1864) noticed that inverse astigmatism often occurred after superior section for an iridectomy or for cataract extraction, surgeons have differed about the type and number of sutures which produce least postoperative astigmatism. The present study, conducted in the Eye Department of the Rajindra Hospital, Patiala, was designed to try to resolve this question in relation to cataract wound closure.

\section{Patients and methods}

One hundred cases of cataract extraction were selected for study. In 50 cases (group A) the sutures were preplaced. Of these 50, 16 had one preplaced suture, 17 had three, and 17 had five. In the other 50 cases (group B) the sutures were postplaced-one postplaced suture in 16 cases, three in 18 cases, and five in 16 cases. Pre- and postoperative keratometry and retinoscopy were done on two follow-up visits, one at about 20 days after operation and the other at six weeks after operation.

Physiological astigmatism was present preoperatively in 82 cases and was absent in 18 . The astigmatism was inverse in 37 ( 45 per cent) cases, direct in 30 ( 37 per cent), and bioblique in 15 ( 18 per cent) (Fig 1 ). The average astigmatism was $I \cdot 19$ dioptres. The axis was at 180 or 90 degrees in 38 cases (Fig. 2). The average radius of the lesser curvature was $7.92 \mathrm{~mm}$ and of the greater curvature $7.70 \mathrm{~mm}$ (range from 6.79 to $9.4 \mathrm{~mm}$ ).

\section{Postoperative results}

\section{ASTIGMATISM}

At the first follow-up examination at 20 days, 5 I cases showed inverse astigmatism and 49 direct astigmatism. The average astigmatism was $5 \cdot 15$ dioptres. The increase in the incidence of inverse astigmatism was only from 37 cases preoperatively to $5 \mathrm{I}$ postoperatively, whereas the increase in direct astigmatism was from 30 to 49 cases. Also out of the 18 cases with no preoperative astigmatism five showed inverse and 13 showed direct astigmatism.

At the second follow-up examination at six weeks 72 cases had inverse astigmatism and 25 had direct astigmatism. Three cases had no astigmatism. The average astigmatism was $2 \cdot 49$ dioptres. The axis of astigmatism was at exactly 90 or 180 degrees

Address for reprints: D. Singh, Rajindra Hospital, Patiala, India in 33 ( 34 per cent) cases at 20 days (Fig. 3) and in 40 cases at six weeks (Fig. 4).

The radius of the lesser curvature had increased on average by $0.59 \mathrm{~mm}$ at 20 days. Between then and six weeks it decreased by $0.5 \mathrm{I} \mathrm{mm}$, so that the increase at the final follow-up was $0.08 \mathrm{~mm}$.

The radius of the greater curvature had decreased by $0.24 \mathrm{~mm}$ at 20 days. Between then and six weeks it had increased by $0.08 \mathrm{~mm}$, so that the decrease at final follow-up was $0.16 \mathrm{~mm}$ (Fig. 5).

Thus there was a decrease or flattening of the lesser curvature and an increase or steepening of the greater curvature during the postoperative

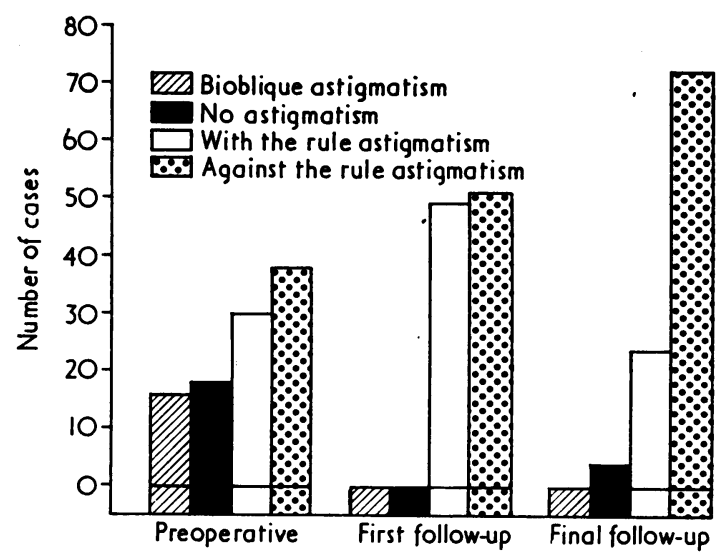

FIG. I Type of astigmatism in 100 cases of cataract extraction

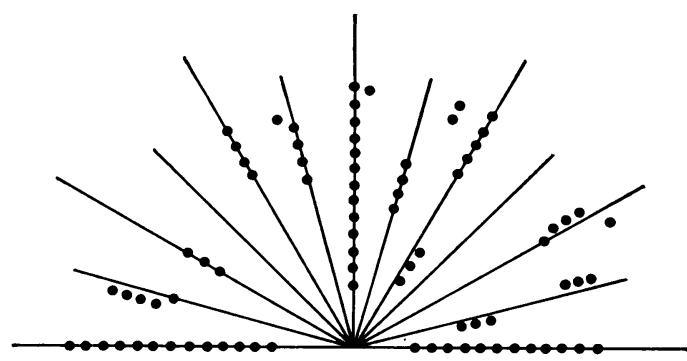

FIG. 2 Distribution of axis of plus cylinder (corresponding to greater curvature) along different meridians in 82 cases of astigmatism (including bioblique astigmatism) before cataract extraction. Each dot represents one case 


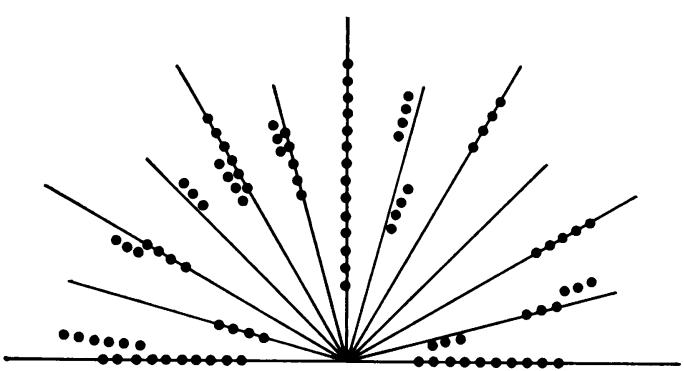

FIG. 3 Distribution of axis of plus cylinder (corresponding to greater curvature) in different meridians in 100 cases of astigmatism 20 days after cataract extraction. Each dot represents one case

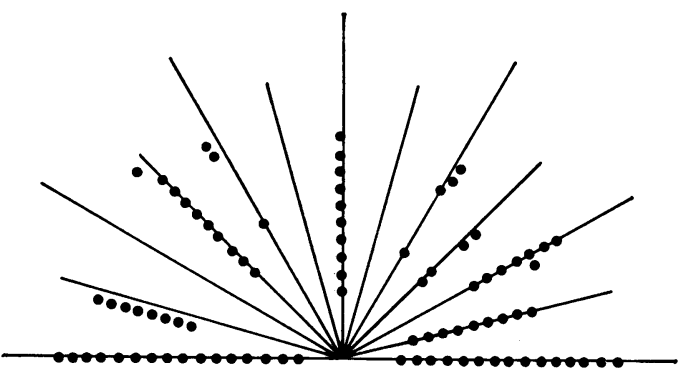

FIG. 4 Distribution of axis of plus cylinder (corresponding to greater curvature) along different meridians in 97 cases of astigmatism 6 weeks after cataract extraction. Each dot represents one case

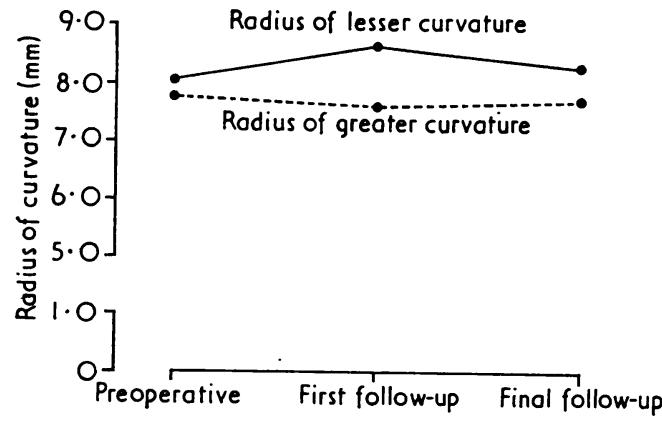

FIG. 5 Mean changes in radii of curvatures

period. The flattening of the lesser curvature was relatively greater than the steepening of the greater curvature during the first 20 days, which accounted for the greater amount of astigmatism. At six weeks the changes were more in the greater curvature than in the lesser curvature. However, there was more variability in the changes in the lesser curvature than in those in the greater curvature. Also the changes that occurred from the first to the final follow-up were opposite to those that
Table Comparison of pre-and postoperative astigmatism

\begin{tabular}{|c|c|c|c|c|}
\hline & \multicolumn{2}{|c|}{$\begin{array}{l}\text { No. of cases with } \\
\text { direct astigmatism }\end{array}$} & \multicolumn{2}{|c|}{$\begin{array}{l}\text { No. of cases with } \\
\text { inverse astigmatism }\end{array}$} \\
\hline & $\leqslant 2 D$ & $>2 D$ & $\leqslant 2 D$ & $>2 D$ \\
\hline Preoperative & 26 & IO & 35 & I I \\
\hline Postoperative & 12 & 10 & 19 & 49 \\
\hline
\end{tabular}

occurred from before operation to the first followup. Similar findings have been observed by Beasley (1967), whereas Lamba and Sood (1971) found the opposite.

In 44 cases the preoperative type of astigmatism did not change after operation. In 24 cases a preoperative direct astigmatism changed to inverse and in 13 cases an inverse changed to a direct. On the whole, the type of postoperative astigmatism tended to be the same as the preoperative (Table). This is in agreement with Floyd (195I).

\section{TYPE AND NUMBER OF SUTURES}

The amount of astigmatism associated with preplaced sutures (group A) was $4.37 \mathrm{D}$ at 20 days and $2.53 \mathrm{D}$ at six weeks, and that associated with postplaced sutures $5.93 \mathrm{D}$ at 20 days and $2.45 \mathrm{D}$ at six weeks (Fig. 6).

Analysis of the amount of astigmatism in groups $A$ and $B$ at 20 days in relation to the number of sutures was as follows: one suture, $5.02 \mathrm{D}$ (group $\mathrm{A}$ ) and $7.20 \mathrm{D}$ (group B); three sutures, $3.33 \mathrm{D}$ (group A) and 5.2I D (group B); five sutures, 4.79 D (group A) and $5.49 \mathrm{D}$ (group B) (Fig. 7). Corresponding figures for the second follow-up at six

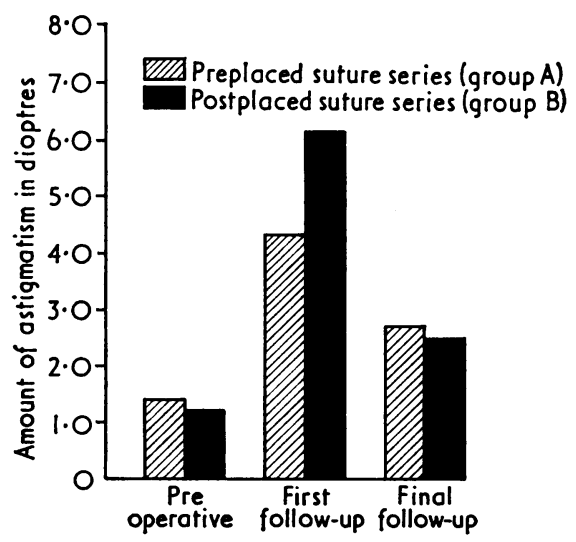

FIG. 6 Amount of astigmatism related to type of suture 
weeks were as follows: $3.69 \mathrm{D}$ and $3.49 \mathrm{D} ; \mathrm{r} \cdot 83 \mathrm{D}$ and $\mathrm{I} \cdot 80 \mathrm{D} ; 2 \cdot \mathrm{I}_{5} \mathrm{D}$ and $2 \cdot 13 \mathrm{D}$ (Fig. 8).

The difference between the average amount of astigmatism at six weeks between pre- and postplaced sutures was insignificant. In both groups an increase in the number of sutures from one to three resulted in a significant decrease in astigmatism. Increasing the number of sutures from three to five did not result in any further decrease in astigmatism-on the contrary, there was a slight increase.

\section{RETINOSCOPY}

Retinoscopy at 20 days gave the following values: spherical + $10.47 \mathrm{D}$; + cylinder on retinoscopy $+2.99 \mathrm{D}$; cylinder on keratometry 5.15 D. The

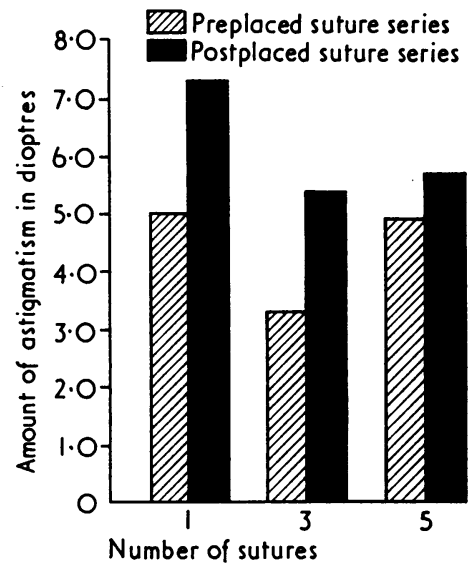

FIG. 7 Distribution of amount of astigmatism between groups $A$ and $B$ at 20 days related to number of sutures

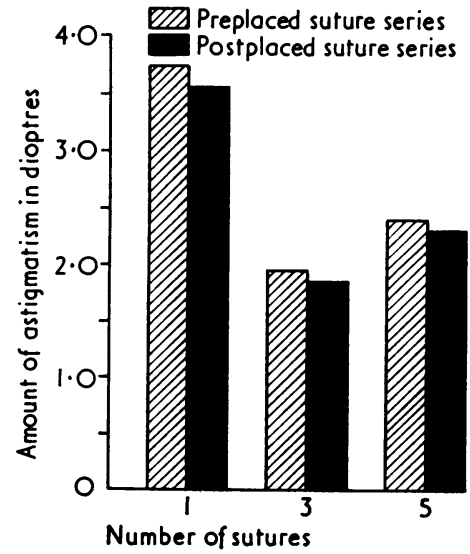

FIG. 8 Distribution of amount of astigmatism between groups $A$ and $B$ at second follow-up (6 weeks) related to number of sutures comparable values at six weeks were $+11 \cdot 00 \mathrm{D}$; $+\mathrm{I} \cdot 77 \mathrm{D}$; and $2.49 \mathrm{D}$, respectively. There was an increase of $0.53 \mathrm{D}$ in the spherical and a decrease of $\mathrm{I} \cdot 22 \mathrm{D}$ in the cylindrical value from first to final follow-up. This is in agreement with Lamba and Sood (r97I). There was no correlation between the amount and axis of cylinder as measured on retinoscopy and keratometry. This is supported by Fonesca Calderia (196r) and Beasley (I967).

\section{STATISTICAL SIGNIFICANCE}

There was no significant difference in the amount of postoperative astigmatism whether pre- or postplaced sutures were used. The decrease in the amount of astigmatism with three sutures was significant. The amount of astigmatism was slightly higher with five sutures than with three, but the difference was not significant.

\section{Discussion}

This study shows that the number but not the type (pre- or postplaced) of sutures used at cataract extraction affect the amount of postoperative astigmatism. Astigmatism was significantly less when three sutures rather than one were used. The amount of postoperative astigmatism with five sutures was slightly higher than with three sutures, but not significantly so. Three sutures are therefore the optimum number to use but it does not matter whether they are pre- or postplaced.

Our results in relation to the number of sutures are supported by Bengisu (r963), Müller (1965), McLean (1967), and Truhlsen (r 968). Taylor (1959), however, preferred five radial and appositional sutures. Nirankari and Khanna (1968) agree with us that it is immaterial whether pre- or postplaced sutures are used in cataract wound closure, although Singh and Goel (1969) disagree.

The preoperative incidence of physiological astigmatism in our cases-82 per cent-is much higher than that reported by some others, as follows: 10.56 per cent (Mugge, 1908); 7.47 per cent (Luhl, 1909); 44.39 per cent (Cavara, 1922); 48. Io per cent (Leibowiez, 1928); 42 per cent (Nirankari and Khanna, I968), 60 per cent (Kapoor, 1965), and 69 per cent (Singh and Goel, 1969). It is almost similar to the 75 per cent of Zamora (1904) and the 79 per cent of Beasley (1967) but less than the 95 per cent reported by Duke-Elder (1949).

Our average astigmatism of $1 \cdot 19 \mathrm{D}$ is higher than the I.OD quoted by Donders (1864), the $0.75 \mathrm{D}$ by Pfalz (1885), the $\mathrm{I} \cdot 04 \mathrm{D}$ by Jackson (1932), the 0.75 to $0.5 \mathrm{D}$ by Sørensen (1944), the $0.97 \mathrm{D}$ by Kapoor (1965), the $0.75 \mathrm{D}$ by Beasley 
(1967), and the 0.5 to $0.75 \mathrm{D}$ by Duke-Elder (1970). Our 38 cases with an axis of astigmatism at 180 or 90 degrees are fewer than those quoted by Singh and Goel (1969). The range of radius of curvature agrees with that found by Tron (1934, 1935).

The tendency for direct astigmatism to increase postoperatively, seen in our cases at first follow-up, may well be a sutural phenomenon, as first described by Floyd (1951) and later by Beasley (1967), and Elenius and Karo (1968). A contrary view has been expressed by Groenholm (I935), Nirankari and Khanna (1968), and Singh and Goel (1969). Our finding that the amount of postoperative astigmatism was unrelated to the preoperative amount accords with the findings of Beasley (1967).

We draw the following conclusions from our study.

I. Healing of the corneal wound after cataract extraction invariably produces an inverse type of astigmatism after six weeks.

2. Astigmatism immediately after operation is high compared with that after six weeks, when it is reduced to almost a half. At six weeks there is an overall decrease or flattening of the lesser curvature and an increase or steepening of the greater curvature.

3. On the whole, postoperative astigmatism tends to be of the same type as preoperatively, especially in cases with preoperatively inverse astigmatism. There is no correlation between the amount of preoperative and postoperative astigmatism.

4. There is no appreciable difference between the change in the amount of astigmatism with pre- or postplaced sutures. Therefore postplaced sutures are in no way inferior to preplaced.

5. The optimum number of sutures, whether pre- or postplaced, is three. Three sutures produce least astigmatism, multiple sutures are better than one, but an increase from three to five does not serve any purpose.

6. The changes observed on retinoscopy show a gradual increase in the spherical value and a decrease in the amount of cylinder up to six weeks. The value of the cylinder required is less than that observed on keratometry; the two bearing no relationship.

\section{Summary}

One hundred cases of uncomplicated cataract with clear corneae had cataract extraction and were examined at 20 days and six weeks after operation. Keratometry was done preoperatively and keratometry and retinoscopy at each of the follow-up visits. The study was undertaken to evaluate the type (whether pre- or postplaced) and the number of sutures (one, three, or five) that produce the least postoperative astigmatism. We found that the type of suture was immaterial but that three sutures produced the least astigmatism.

\section{References}

BEASley, H. (1967) Trans. Amer. ophthal. Soc., 65, 168 BENGisu, Ü. (1963) Oto Nöro Oftal (Istanbul), 18, 9 CAVARA (1922) Quoted by P. M. Kapoor (1965) Indian F. med. Res., 53, 565 DONDERS (1 864 ) Quoted by S. Duke-Elder (196I) 'System of Ophthalmology', vol. II, p. 94. Kimpton, London DUKE-ELDER, S. (I949) 'The Practice of Refraction' (1954) p. I07. Mosby, London (1970) 'System of Ophthalmology', vol. V, pp. 275, 278, 375-76, 406. Kimpton, London elenius, v., and Karo, T. (1968) Eye, Ear, Nose Thr. Monthly, 47, 66 FLOYD, G. (195I) Amer. F. Ophthal., 34, I525 FONESCA CAlDERIA, J. A. (196I) Arch. bras. Oftal., 24, I84 GROENHOLM, v. (I935) Finska läk.-sällsk. handl., 78, 286 jackson, e. (1932) f. Amer. med. Ass., 98, 132 KAPOOR, P. M. (1965) Indian F. med. Res., 53, 565, 1014 LAMBA, P. A., and SOOD, N. N. (I97I) Indian Y. Ophthal., 19, 7, LEIBOWIEz (1928) Quoted by P. M. Kapoor (1965) Indian F. med. Res., 53, 565 LUHL (1909) Quoted by P. M. Kapoor (1965) Ibid., 53, 565 mClean, J. M. (1967) Trans. Amer. ophthal. Soc., 65, I68 MUGGE (1908) Quoted by P. M. Kapoor (1965) Indian F. med. Res., 53, 565 MÜlleR, w. (1965) Ophthal. Lit. (Lond.), 19, 669 NIRANKari, M. S., and KhanNa, K. K. (1968) Orient. Arch. Ophthal., 6, 8 PFAlz (1885) v. Graefes Arch. Ophthal., 31, pt I, 201 SINGH, Y. P., and GOEL, v. K. (1969) F. All-India ophthal. Soc., 17, 33 SORENSEN (1944) Acta ophthal. (Kbh.), 22, 34I TAYLOR, D. M. (1959) Amer. F. Ophthal., 48, 660 TRON (1934) v. Graefes Arch. Ophthal., 132, 182 (1935 Ibid., 133, 2 I I

TRUHLSEN, S. M. (1968) Amer. $\mathcal{F . ~ O p h t h a l . , ~ 6 6 , ~} 947$

ZAMORA (1904) Quoted by P. M. Kapoor (1965) Indian F. med. Res., 53, 565 